\title{
O impacto da nova Lei Nacional de Adoção no acolhimento institucional: o ponto de vista de psicólogos e assistentes sociais que integram as equipes técnicas
}

The impact of the new Adoption Law in residential care: the perspective of psychologists and social workers who are part of professional teams

El impacto de la nueva Ley Nacional de Adopción en el amparo institucional: el punto de vista de psicólogos y asistentes sociales que integran los equipos técnicos

\section{Milena Leite Silva* \\ Dorian Mônica Arpini ${ }^{* *}$}

\begin{abstract}
Resumo
O estudo é uma pesquisa qualitativa realizada com oito psicólogos e assistentes sociais trabalhadores em instituições de acolhimento institucional no interior do Rio Grande do Sul. O objetivo geral foi conhecer como eles entendem as mudanças da nova Lei Nacional de Adoção (Lei 12.010/2009), justifica-se por conhecer o impacto da legislação nas instituições. Realizaram-se entrevistas semidirigidas com os profissionais, técnica que permite conhecer em profundidade suas reflexões, já que esse é um dos aspectos importantes nos estudos qualitativos. Utilizou-se da análise de conteúdo proposta por Bardin, para análise dos resultados. Estes denotam mudanças na escuta dos acolhidos e a presença do plano individual de atendimento, valorizando o resgate de suas histórias. As considerações finais trazem a importância dessa nova abordagem realizada pelos profissionais, a qual pode contribuir para consolidar a legislação, como a construção de um plano de trabalho conduzindo ao encerramento do acolhimento por meio da reinserção familiar ou adoção.
\end{abstract}

Palavras-chave: Crianças abrigadas. Leis. Relações familiares. Crianças. Adolescentes.

\begin{abstract}
This study is a qualitative research, carried out with eight psychologists and social workers of residential care in the interior of Rio Grande do Sul. Its general aim was to know if they understand the changes of the new Adoption Law (Law 12.010/2009), and it is justified by the
\end{abstract}

\footnotetext{
Mestra em Psicologia pela Universidade Federal de Santa Maria (UFSM), psicóloga.

* Professora no Programa de Pós-graduação em Psicologia da UFSM, psicóloga.
} 
need to acknowledge the impact of laws regarding institutions. Semidirected interviews were carried out with professionals, aiming for indepth knowledge of their reflections, considering that is a core aspect in qualitative studies. Content analysis, as proposed by Bardin, was the chosen method concerning the analysis of the results. Results show evidence of change in the way professionals try to understand people in residential care, as well as the presence of the Individual Plan of Care, valuing accounts of their life histories. Final considerations highlight the importance of this new approach of the professionals, considering that it may contribute to consolidate the legislation, such as a working plan that aims at the interruption of residential care through family reinsertion or adoption.

Keywords: Sheltered children. Laws. Family relations. Children. Adolescents.

\section{Resumen}

Este estudio es una pesquisa cualitativa realizada con ocho psicólogos y asistentes sociales que trabajan en instituciones de amparo institucional en el Estado de Rio Grande del Sur. El objetivo general fue conocer cómo ellos entienden los cambios de la nueva Ley Nacional de Adopción (Ley 12.010/2009), se justifica por conocer el impacto de la legislación en las instituciones. Se realizaron entrevistas semi-dirigidas con los profesionales, técnica que permite conocer en profundidad sus reflexiones, pues este es uno de los aspectos importantes en los estudios cualitativos. Se utilizó el análisis de contenido propuesto por Bardin para análisis de los resultados. Estos denotaron cambios en la escucha de los amparados y la presencia del Plano Individual de Atendimiento, valorizando el rescate de sus historias. Las consideraciones finales muestran la importancia de ese nuevo abordaje realizado por los profesionales, que puede contribuir a la consolidación de la legislación, como la construcción de un plan de trabajo dirigido al cierre del amparo por medio de reinserción familiar o adopción.

Palabras clave: Niños abrigados. Leyes. Relaciones familiares. Niños. Adolescentes.

\section{As famílias cujos filhos se encontram sob a medida de proteção chamada de acolhimento institucional parecem contar com um conjunto de sofrimentos nem sempre compreendidos pelos profissionais que trabalham com crianças e adolescentes pertencentes a famílias em situação de}


vulnerabilidade social (Arpini \& Quintana, 2009; Arpini, 2013; Silva, Polli, Sobrosa, Arpini \& Dias, 2012). Ao contrário do que apressadamente poderia se pensar no senso comum, Azôr e Vectore (2008), em pesquisa realizada, constataram que o momento da institucionalização dos filhos é vivido com extremo sofrimento pela família, que sente tristeza e revolta por ter de se afastar dos filhos, além de medo de que eles venham a ser adotados.

Além de terem de lidar com todas essas angústias, muitas vezes, as famílias podem encontrar ainda mais uma sobrecarga, relacionada à forma desqualificada com que os profissionais podem percebê-las em função da necessidade de utilização da medida de acolhimento (Arpini, 2013; Silva, Polli, Sobrosa, Arpini \& Dias, 2012). Em tempos de vigência da nova Lei Nacional de Adoção (NLNA) (Lei n. 12.010, 2009), a qual propõe uma relação mais próxima entre família e instituição, tendo em vista a reintegração familiar a ser trabalhada em um período máximo de dois anos de acolhimento institucional (salvo determinação judicial contrária), as relações entre a família e a instituição tornam-se fundamentais, e necessitam ser foco de atenção em novos estudos.

Dessa forma, se os profissionais passam a considerar a família o berço das intervenções que resultarão em progressos na área da infância e adolescência (Arpini \& Quintana, 2009; Arpini, 2013; Petrini, 2003), suas problemáticas necessitam ser tratadas com cuidado, principalmente considerando que essa família pode ter sido, em algum momento, mal compreendida ou negligenciada por profissionais e, ou, instituiçôes. A NLNA, ao propor, já no início do acolhimento institucional, a inclusão da família no plano individual de atendimento da criança acolhida e ao enfatizar a temática da reintegração familiar (retorno de uma criança/adolescente à sua família após um período de afastamento, no qual foi cumprida em instituição de acolhimento a medida de proteção a essa criança) destaca claramente uma ênfase na abordagem familiar. Nesse sentido, é importante destacar que a Lei faz uma revisão dos pressupostos já presentes no Estatuto da Criança e do Adolescente (Lei n. 8.069, 1990), enfatizando a convivência familiar e comunitária, e colocando a adoção como medida excepcional.

Tal aspecto é também objeto de reflexão e mudança, ao tratar do término do acolhimento que deve se realizar em um período menor do que vinha acontecendo. Esses aspectos poderão operar uma grande reflexão acerca da cultura da institucionalização no País, aumentando a inserção da família nesse processo (Arpini, 2003; Arpini, 2013; Rizzini \& Rizzini, 2004). Anteriormente à nova lei, estudos vinham refletindo sobre as difíceis consequências trazidas por um período de institucionalização prolongado, apontando para dificuldades 
que poderiam surgir no desenvolvimento emocional de crianças acolhidas por longo período e pela possibilidade de romper-se, de forma definitiva, o vínculo com a família (Arpini \& Quintana, 2009; Janczura, 2008; Siqueira \& Dell'Aglio, 2006).

As transformações legislativas que hoje se traduzem em NLNA são, na verdade, marcos históricos alcançados por meio da luta de diversos atores sociais ligados as áreas da infância e adolescência que buscaram maiores garantias para essa população, que, mais tarde, seriam concretizadas na Constituição de 1988 e no ECA (Lei n. 8.069, 1990). Pela doutrina da proteção integral, as crianças e os adolescentes passam a ser vistos como sujeitos em desenvolvimento, que têm seus direitos assegurados com prioridade absoluta (Janczura, 2008).

O ECA propôs uma mudança radical de paradigma por meio da doutrina da proteção integral, representando um grande avanço e sendo recebido com entusiasmo pelos atores que vinham compreendendo a infância e a adolescência de maneira diferenciada e que, havia anos, buscavam a proteção e a garantia dos direitos de toda e qualquer criança e adolescente.

O ECA definiu que a institucionalização deveria ser uma medida de proteção temporária, mas não definiu o tempo máximo que crianças e adolescentes poderiam permanecer em uma instituição, preconizando apenas que esse período deveria ser breve e que a utilização da medida deveria ser de caráter temporário e excepcional. Assim, a lei 12.010/2009 (NLNA) tende a tornar o contato das instituiçóes de acolhimento com o Judiciário ainda mais estreito, uma vez que preconiza um tempo máximo para o acolhimento e a necessidade de revisão periódica da medida, estimulando o retorno da convivência familiar das crianças e adolescentes acolhidos.

A convivência familiar e comunitária (Lei n. 8.069, 1990, art. 19), já proposta pelo ECA, foi assim reforçada por meio de três incisos, os quais estabelecem que a situação jurídica da criança acolhida em uma instituição deve ser reavaliada a cada seis meses $\left(\$ 1^{\circ}\right)$, o tempo máximo de permanência em acolhimento institucional será de dois anos, salvo comprovada necessidade que atenda ao interesse da criança $\left(\$ 2^{\circ}\right)$ e a manutenção ou reintegração de criança ou adolescente à sua família terá preferência em relação a qualquer outra ação $\left(\$ 3^{\circ}\right)$. Ainda, tendo em vista a agilidade no atendimento às necessidades de cada criança e adolescente acolhido, instituiu-se a elaboração de um plano individual de atendimento (art. 101, IV, $\$ 4^{\circ}$ ).

As instituições que antes se chamavam abrigos, com a NLNA, passam a ser denominadas instituições de acolhimento. Acolher, para Ferreira (1977), significa hospedar, receber, atender e tomar em consideração. A mudança 
na nomenclatura e principalmente no tempo de institucionalização, tendo em vista a facilitação da reintegração familiar, é muito importante. Dados apontados por Silva (2004) em pesquisa realizada nos abrigos brasileiros revelam que mais da metade das crianças permanece nas instituições por mais de dois anos, muitas delas saindo desses locais quando completam 18 anos, momento em que se passa a problematizar o resgate dos vínculos familiares. Tal estudo revelou ainda a dificuldade encontrada, mesmo após a implantação do ECA, de fazer do afastamento de crianças e adolescentes de suas famílias algo breve e excepcional. A criação de uma nova lei, que defina os atores responsáveis por esse resgate dos vínculos e do limite de tempo para que ocorra parece se constituir em uma das ações importantes para alcançar os princípios da brevidade e da excepcionalidade ainda não alcançados.

Azambuja (2002) aponta que esse tempo de permanência pode chegar a cinco ou até mais anos. Estudos apontam que os efeitos da institucionalização prolongada são expressos por um empobrecimento da subjetividade, em razão da perda de relacionamentos significativos para crianças e adolescentes, atrelado às dificuldades que algumas instituições podem apresentar para manter um atendimento individualizado para crianças, adolescentes e as famílias (Associação Brasileira Terra dos Homens, 2002; Siqueira \& Dell'Aglio, 2006). As consequências dessa situação, para quem foi acolhido, podem ser as dificuldades de se autogerenciar, de se socializar e de manter vínculos afetivos na vida adulta, diminuindo as chances de uma reinserção social adequada. Conforme o tempo passa e vai sendo vivido no interior de uma instituição, mais arraigada e internalizada se torna a lógica institucional, a ponto de se constituir como o único parâmetro existente para crianças e adolescentes se referenciarem ao longo de suas vidas (Silva, 2002).

Com intuito de evitar tais consequências e atender integralmente crianças e adolescentes, tal como a palavra acolher sugere, a nova lei prevê o Plano Individual de Atendimento (PIA), a ser realizado pelas equipes das instituiçôes de acolhimento. Esse plano (Lei n. 12.010, 2009) deve levar em conta as necessidades da criança, facilitando a reintegração desta à família, impedindo que situações encontradas anteriormente em instituições de atendimento ditas totais se repitam (Goffman, 1961), em que o tratamento dispensado era idêntico para todas as crianças e os adolescentes, dos quais se subtraía sua intimidade e individualidade, conforme os mergulhavam nas regras funcionais e disciplinares, as quais excluíam o componente subjetivo de qualquer ação (Associação Brasileira Terra dos Homens, 2002).

O plano individual, como o próprio nome diz, deve atender às demandas das crianças por meio da escuta individualizada destas, as quais, dessa forma, 
passam a desempenhar um papel ativo no seu próprio plano de atendimento. Essa nova modalidade abre espaço para a compreensão do componente subjetivo e do reconhecimento da singularidade presente em cada situação. Outro aspecto importante a ser destacado é a participação dos pais ou responsáveis nesse momento inicial do acolhimento, pois a família também deve ser ouvida e fazer parte da elaboração do plano, definindo-se açôes de acompanhamento tanto para a família quanto para a criança ou adolescente acolhido.

O fato de as entidades serem acompanhadas em suas ações pelo Judiciário, a cada seis meses, pode agilizar a individualização do atendimento e consequentemente a reinserção familiar, pois estudo de Silva, Mello e Aquino (2004) refere que apenas $42,4 \%$ das entidades de atendimento pesquisadas no Brasil tinham como rotina enviar relatórios periódicos acerca da situação jurídica de crianças e adolescentes que se encontravam em medida de acolhimento. Considerando que é a autoridade judiciária que, em última instância, decide pela reintegração familiar ou pela continuidade do acolhimento, temos razões significativas para destacar a importância dessa aproximação.

Se, de acordo com a NLNA, o período de institucionalização fica reduzido, poderá ocorrer uma nova forma de vinculação entre famílias e instituiçōes, uma vez que o vínculo se torna uma problemática central a ser trabalhada (Janczura, 2008). Resgatar ou, muitas vezes, construir esse vínculo será uma tarefa importante, pois o estreitamento desses laços poderá contribuir para que sejam criadas e fortalecidas práticas em torno da perspectiva da NLNA, as quais alcancem verdadeiramente as famílias. Nesse sentido, com o fato de as instituições contarem atualmente com equipes técnicas capacitadas a trabalharem os vínculos entre família, crianças e instituiçôes, o trabalho se torna mais promissor com relação ao alcance das propostas da lei, tendo em vista que a formação de psicólogos e assistentes sociais prepara-os tecnicamente para lidarem com tais demandas.

O ganho das equipes técnicas no trabalho com as famílias e com os próprios acolhidos parece ser uma consequência positiva da NLNA. Um exemplo dessa situação pode ser evidenciado na cidade onde o estudo foi realizado, pois, no ano de 2001, quando o Estatuto da Criança e do Adolescente (Lei no 8.069/1990) já vigorava, não existiam técnicos de Psicologia nem de Serviço Social trabalhando nas instituiçóes, as quais contavam apenas com estágios de acadêmicos de universidades. Nesse contexto, a construção do plano de atendimento individual, o PIA, é uma das atividades que caracterizam o trabalho desses profissionais, uma das tarefas propostas pela NLNA, o qual 
começa a se delinear pela escuta da criança e do adolescente que chegam à instituição.

Considerando tais apontamentos, o objetivo deste estudo foi conhecer como psicólogos e assistentes sociais que atuam em instituições de acolhimento institucional percebem as mudanças propostas pela NLNA (Lei 12.010/2009). Assim, conhecer o impacto da atual legislação no interior das instituições foi a justificativa para a realização do estudo. Acredita-se que a relevância social do estudo está centrada na importância do tema e da compreensão das mudanças que devem advir das alteraçôes propostas pela legislação. Tendo em vista o objeto de estudo, qual seja, a medida de proteção acolhimento institucional, é, sem dúvida, de muita relevância atentar para o trabalho desenvolvido pelos profissionais nessas instituições, tendo como parâmetro a atual legislação.

\section{Método}

\section{Local de investigação}

A pesquisa, de caráter qualitativo, foi realizada nas instituições que atendem à medida de acolhimento institucional na cidade onde o estudo foi realizado. No total, foram envolvidas no estudo cinco instituições, sendo que duas das instituições participantes contam com a mesma equipe técnica. As instituições acolhem bebês, crianças e adolescentes e, juntas, totalizavam 93 acolhidos no momento da realização da pesquisa. A instituição 1 é uma organização não governamental, destinada ao atendimento de crianças e adolescentes. A capacidade máxima para acolhimentos é de cem pessoas e, durante a realização do estudo, havia 54 acolhimentos. A instituição 2 é uma organização não governamental, destinada a atender meninos na faixa etária de 4 a 12 anos e, na realização da pesquisa, contava com 4 acolhimentos. A instituição 3 é uma instituição não governamental direcionada ao atendimento de meninas de $0 \mathrm{a}$ 12 anos e contava com 21 meninas acolhidas durante a realização do estudo. A instituição 4 é governamental, atende a adolescentes do sexo masculino e, durante a realização da pesquisa, contava com 6 adolescentes acolhidos. A instituição 5 é governamental e atende adolescentes do sexo feminino, sendo que, durante a realização do estudo, havia 8 adolescentes acolhidas.

\section{Participantes}

Os profissionais que integraram o estudo foram 8 , dos quais 4 eram assistentes sociais e 4 eram psicólogos, e representavam a totalidade dos profissionais que atuavam nesse cenário, na cidade onde o estudo foi realizado. 
Seus dados sociodemográficos demonstraram que sua idade média era de 31 anos e que tinham, no mínimo, 2 anos e, no máximo, 6 anos de atuação profissional, sendo que o período mínimo que esses profissionais trabalhavam na instituição de acolhimento era de 7 meses e, o máximo, de 3 anos.

\section{Instrumentos}

Para a realização do estudo, foram utilizadas entrevistas semidirigidas de questóes abertas (Turato, 2003), pelas quais se buscou compreender em profundidade as experiências dos psicólogos e assistentes sociais em relação à NLNA. Houve uma troca dinâmica na condução da entrevista, isto é, as questôes iam sendo colocadas ora pelo entrevistador ora pelo entrevistado, o que facilitou a coleta de informaçôes baseada no discurso livre do entrevistado, mediante a introdução de tópicos pelo entrevistador.

Para conhecer em profundidade a opinião dos profissionais acerca do acolhimento institucional a partir da NLNA, utilizaram-se os seguintes tópicos-guia, que representam os objetivos específicos deste trabalho: "quais são, na sua opinião, as principais alterações propostas pela NLNA?"; "quais são as principais alterações ocorridas no contexto do seu trabalho na instituição?". As entrevistas foram realizadas individualmente, nas dependências das próprias instituições, em local adequado e com privacidade.

\section{Procedimento de coleta dos dados}

Inicialmente o projeto foi apresentado para as instituições e, após a concordância, o termo de autorização institucional foi assinado e deu-se andamento à pesquisa. Foi realizado um agendamento com cada participante das entrevistas, as quais foram feitas nas dependências das instituiçõos, em local adequado e com privacidade, entre os meses de janeiro e fevereiro de 2011. No momento da entrevista, foram explicados aos entrevistados os objetivos do estudo e, após a concordância deles, deu-se a assinatura do termo de consentimento livre e esclarecido. As entrevistas foram gravadas e depois transcritas, tendo duração de cerca de 40 minutos.

Essa pesquisa está respaldada nas diretrizes e normas que regulamentam a pesquisa envolvendo seres humanos (Resolução n. 196, 1996; Resolução n. 16, 2000), tendo parecer favorável do Comitê de Ética e Pesquisa (protocolo de aprovação no 0127.0.243.000-10) da instituição de ensino superior na qual os pesquisadores atuam. Por causa da preocupação ética e da garantia do anonimato dos participantes, não foram identificados o núcleo profissional e a instituição em que trabalham. 


\title{
Procedimentos de análise dos dados
}

A análise dos dados foi realizada segundo a proposta de análise de conteúdo (Bardin, 2004), a qual se caracteriza por um conjunto de instrumentos metodológicos que se aplicam aos discursos, analisando as comunicações. Primeiramente as entrevistas foram analisadas individualmente em profundidade e, depois desse momento, procedeu-se a uma segunda etapa, que se constituiu da análise conjunta do material, com posterior construção das categorias. Para a construção das categorias, levou-se em conta a força discursiva, ou seja, a presença com que os elementos apareceram nos discursos, sua repetição ou mesmo os sentimentos a eles associados. Duas categorias serão apresentadas a seguir: a escuta da criança e do adolescente; e a construção do plano individual de atendimento.

\section{Resultados e discussão}

\section{A escuta da criança e do adolescente}

A NLNA propõe que os técnicos das instituições realizem um plano individualizado de atendimento para cada criança e adolescente que seja acolhido, de forma que a escuta atenta de cada criança passa a ser uma prioridade e o ponto inicial que norteará o plano individual:

\begin{abstract}
[...] os pais simplesmente negligenciam a criança, e a criança, ela chega no acolhimento muitas vezes achando que porque ela foi ruim, ela matô aula... e ela não matô aula, ela não dormiu na hora que ela devia dormi, ela não tava alimentada, ela simplesmente não foi orientada assim, 'filho agora tu vai pra aula', nem que não levasse, mas isso é responsabilidade de um adulto, orientá uma criança. E muitas dessas crianças chegam aqui, a primeira coisa que a gente faz é ouvi da criança por que que ela tá aqui; que elas contem a história, 'porque que tu tá aqui?', e a maioria das vezes en escuto isso: 'ah, porque eu fugia de casa, porque en matava aula?. (P8)
\end{abstract}

Essa maneira de conduzir as relações dá oportunidade à criança e ao adolescente de falarem sobre o que aconteceu, sobre como entendem o que está acontecendo com as relações familiares e os sofrimentos decorrentes das separações impostas pela medida, superando a busca de culpados pela institucionalização. Esse aspecto parece bastante importante, pois proporciona um espaço de continência, permitindo que se abordem o desamparo, a violência e a sobrecarga psíquica de que pode ter sido alvo uma criança ou 
um adolescente que se encontra em acolhimento. Entretanto, muitas vezes, o trabalhador da instituição pode se identificar com a dor da criança, não apenas por ela não estar com sua família, mas também pelos motivos que geraram esse afastamento, não conseguindo abordar esses temas (Arpini, 2003; Arpini \& Quintana, 2009; Arpini, 2013; Marin, 1999).

\begin{abstract}
A criança e o adolescente trazem consigo as marcas de sua vida familiar e institucional. Ouvi-los sobre elas é essencial para que possam se sentir acolhidos e verdadeiramente convidados a se inserir no abrigo. $\mathrm{O}$ momento e a forma de entrada na instituição demarcam as possibilidades da saída da entidade. Isso significa que todas as atitudes de recepção são significativas para a qualidade do percurso que a criança e o adolescente poderão ter nas demais etapas do processo de acolhimento (Bernardi, 2010, p. 100).
\end{abstract}

Se os atores institucionais encontram dificuldades, ao abordar as temáticas que levam as crianças às instituiçôes, podem acabar por não construir um espaço de acolhida para o sofrimento, o que pode contribuir para que a criança entenda que ela mesma gerou sua institucionalização, que é culpada por tudo que lhe aconteceu e que esse é um assunto que deve ser silenciado.

Essa também é a posição abordada por Marin (1999) e Arpini \& Quintana (2009), quando referem que, para se trabalharem questôes tão mobilizadoras como o são aquelas que se referem à perda, ao abandono e à falta, é preciso contar com um apoio, tanto no nível afetivo quanto intelectual. "Se não se sabe o sentido de falar com a criança a respeito de sua história, e da importância de poder ter claro qual o sentido do abandono vivido, a possibilidade de tolerar a angústia provocada por essa vivência fica muito limitada” (Marin, 1999, p. 109). Trabalhar a história de vida de cada criança e adolescente que está em acolhimento permite que se vá além do termo que pode reduzi-los a "crianças e adolescentes de abrigo". Essas crianças e adolescentes não são sujeitos sem história e é preciso acompanhá-los nessa busca, pois a "reflexão sobre a própria história é o que torna possível que esta, por mais difícil que seja, possa se transformar no ponto de partida para a construção de outra: a história que será sonhada e realizada pela própria criança" (Temer, 2008, p. 1).

Nesse sentido, a continuidade do discurso desse mesmo profissional sintetiza:

[...] é bem sofrido também pra gente - tu tem que acalentá um sofrimento de uma criança que, às vezes, tu não compreende, tu tem que fazer com que ela compreenda - então a gente tem que 
se distanciá dessa questão afetiva e deixá lá fora, senão complica bastante, é criança, né. (P8)

Sabe-se que a atuação dos profissionais do acolhimento institucional é de extrema complexidade, exigindo muita sensibilidade, pois seu cotidiano de trabalho é lidar com o desamparo: "Mas como que eu vou deixar acontecer o sofrimento ali, com aquele conteúdo? Não que eu vá vasculhar, mas eu deixo, eu me disponho pra escuta, o que é diferente" (P4).

Essa disposição dos profissionais para escutar e acolher a história vivida pelas crianças, proporcionando diferentes momentos para essa escuta seja possível, ajuda que crianças e adolescentes acolhidos "possam se apropriar de seu passado, conhecer-se no presente e se preparar para o futuro" (RossetiFerreira, Solon \& Almeida, 2010, p. 63). É por isso que superar essas dificuldades, que são o dia a dia no trabalho dos profissionais, e trabalhar sobre os motivos da entrada da criança na instituição pode contribuir para construir, lentamente, os primeiros aspectos que podem facilitar a reintegração familiar, abrindo uma via de comunicação com a criança acerca de sua família e suas fantasias sobre o acolhimento, e da possibilidade de integrar uma história de vida que é, frequentemente, marcada por rupturas, afastamentos e fragilidades. Winnicott (2005) pontua que é em torno de coisas aparentemente pequenas aos olhos do adulto que circula a imaginação infantil. Dimensionam-se, assim, as fantasias das crianças em relação a questões maiores, como o rompimento dos laços e a saída de casa.

Dessa forma, autores como Azôr e Vectore (2008), e Bernardi (2010) sugerem que o acolhimento institucional se torna mais qualificado conforme a acolhida da criança ou do adolescente na instituição inclua não apenas a apresentação do espaço físico, das pessoas e das normas e rotinas institucionais, mas o esclarecimento dos motivos do acolhimento e de sua condição provisória, "sem atribuir à família qualquer conotação negativa, respeitando o tempo da criança para falar sobre o assunto" (Azôr \& Vectore, 2008, p. 87).

Pouco a pouco, faz-se necessário que a criança vá compreendendo que a medida tomada ajudou a manter sua integridade e que a instituição de acolhimento cumpre uma função provisória até que novos caminhos sejam construídos (Paiva, 2004). Essa primeira acolhida já pode sinalizar um passo em direção à reintegração familiar, a qual passa a ser uma responsabilidade das entidades de acolhimento a partir da NLNA (Lei 12.010, 2009). Contudo, apesar da difícil tarefa que lhes cabe, pôde-se identificar que o 
diálogo acerca do papel da instituição tanto para a criança quanto para a família parece estar sendo construído pelos profissionais das instituições pesquisadas.

A construção do plano de atendimento individual (PIA)

Imediatamente após o acolhimento da criança ou do adolescente, a entidade responsável pelo programa de acolhimento institucional ou familiar elaborará um plano individual de atendimento, visando à reintegração familiar, ressalvada a existência de ordem escrita e fundamentada em contrário de autoridade judiciária competente, caso em que também deverá contemplar sua colocação em família substituta, observados as regras e os princípios desta Lei (Lei n. $12.010 / 2009$, art. $2^{\circ}$, alterando o parágrafo $\$ 4^{\circ}$ do artigo $101 \mathrm{da}$ Lei n. 8.069/1990 - ECA).

Tal plano é uma novidade apontada pelos participantes, que verbalizaram falas como as seguintes: "A gente não vinha fazendo o PIA, a gente vinha fazendo uma guia de acolhimento" (P1). "Hoje em dia tem toda essa questão, esse plano individual também que a gente faz pra juiza quando a criança chega aqui. Tu tem que fazer o plano com tudo, todas as programaçôes, sabe, com as açôes, tudo que a gente vai fazer" (P5).

O plano individual de atendimento é uma estratégia para tornar a medida de acolhimento mais singular, uma ideia que já estava presente no Estatuto, mas que não havia ainda sido objeto de uma ação específica para concretizar essa individualização da medida. O PIA contribui para tornar a criança e o adolescente ativos no decorrer do acolhimento institucional.

A oitiva da criança fica muito centrada nesse processo; de avaliá sim o desejo dessa criança, mas sempre com o mote dessa questão de como que vai ser o amanhã dessa criança? No caso da criança, se ela vai voltá pra familia, se ela vai pra uma família substituta; no caso de um adolescente, quais são os projetos futuros. (P8)

Incluir a criança ou o adolescente no PIA é partir da premissa de que eles são sujeitos de direitos e que, por isso, devem emitir opiniões e participar das decisões que lhes digam respeito. Pesquisa realizada antes de a nova Lei de Adoção entrar em vigor mostrou que as falas das crianças e dos adolescentes não são registradas na mesma forma e proporção que as dos adultos em 
situaçôes de decisão sobre o acolhimento institucional. Segundo Bernardi (2005), nessas situações, priorizam-se as pessoas que falam em nome da criança e do adolescente e não a própria fala destes. De acordo com a autora, conforme aumenta sua idade, aumentam as chances de suas vozes serem ouvidas e tornadas relevantes.

Para Sayão (2010), o PIA é um documento dinâmico que pode ser reformulado sempre que necessário, cujo objetivo principal é acompanhar o movimento presente na trajetória de vida da criança e do adolescente. As ações realizadas a partir desse plano tendem a reconstruir significativamente "práticas já superadas onde os números do prontuário eram os mais importantes e a voz da criança não fazia parte dos dados existentes sobre ela” (Sayão, 2010, p. 122).

A entrada de uma criança em instituição de acolhimento, dentro da mudança de paradigma proposta pela NLNA e com vistas à realização do PIA, impõe algumas perguntas a esses profissionais: "Como acolher alguém que desconheço e com quem posso ficar por pouco tempo?"; "Como compreender essa pessoa e ajudar no que ela precisa?"; "Como garantir a individualização dessa medida dentro de uma dinâmica que se estabelece dentro de um grupo?"; "Como escutar e dar voz se não estou certo de saber lidar com o que vou escutar?” (Bernardi, 2010).

Todas essas indagações podem ser levadas aos profissionais com a chegada do PIA, cuja elaboração passa a ser de responsabilidade dos técnicos das instituições de acolhimento, sendo realizado a partir da escuta da criança ou do adolescente e de seus pais ou responsáveis, ou seja, no momento da entrada na instituição, a família já deve ser ouvida e inserida nas ações tomadas no decorrer da medida.

Alteraçôes aí do PIA, né, o plano individual de atendimento de cada criança, obrigatório, apresenta no máximo em dez dias, assim que a criança entra pra acolhimento, e já no PIA consta as perspectivas de acolhimento, adoção e trabalho com a família. Então isso assim veio pra, uma das prioridades. (P7)

O PIA inclui a avaliação da equipe multiprofissional, os compromissos firmados com pais ou responsáveis pela criança ou pelo adolescente institucionalizado e ainda uma indicação das atividades que serão desenvolvidas tanto com a criança ou com o adolescente acolhido quanto com seus pais ou responsáveis (Lei n. 12.010, 2009, art. 20, alterando o art. 101, $\$ 6^{\circ}$, 
do ECA). Para Bernardi (2010), o PIA busca garantir que a permanência de uma criança ou um adolescente em acolhimento institucional, mesmo que a medida seja provisória e excepcional, assegure que esse período seja importante em suas vidas, contribuindo para trabalhar seus projetos de vida no interior das instituições.

\begin{abstract}
O plano que era - eu não tava aqui, mas eu sei que é uma coisa que não se fazia, né, antigamente - mas, hoje em dia, quando ele chega, a primeira coisa que a gente faz quando a criança chega é "vamo começá a dá jeito de começá a fazê o plano individual". E informaçôes seguidas pro Juizado da Infância, toda semana a gente tá fazendo visitas e colhendo informação. Eu não sei como era antigamente, mas - eu não tava aqui - mas todas as instituiçôes eram assim, era mais largado. (P5)
\end{abstract}

O plano de atendimento individual torna criança e adolescente protagonistas do acolhimento, os quais colaboram para direcionar as açôes que serão desenvolvidas ao longo dos dois anos de permanência máxima na instituição. A participação efetiva da criança e do adolescente permite que o plano responda de fato às suas necessidades. A nova relação estabelecida com a família, incluída no PIA, também pode ser pontuada como uma mudança no contexto do trabalho, realçada por alguns profissionais. De acordo com Bernardi (2010), o PIA inclui especialmente as possibilidades de intervir com a família, seja ela de origem ou substituta, favorecendo a reintegração familiar, outra ação incentivada pela NLNA.

Autores, como Arpini e Quintana (2009), Arpini (2013) e Rizzini e Rizzini (2004), têm se debruçado sobre essa temática, enfatizando que a intervenção nas famílias pode contribuir para que a medida de acolhimento seja, de fato, transitória e que o momento da institucionalização sirva para a família se organizar de forma diferente, sendo auxiliada naquilo que precisa. A nova lei tenta ampliar o universo das intervenções, pois, até bem pouco tempo, trabalhava-se com as crianças de forma isolada, em vez de dialogar com os diversos adultos envolvidos com ela (Fonseca, 2002).

Ampliar as intervenções implica refletir sobre a relação entre famílias e instituições. A redução do tempo no acolhimento institucional e a promoção da reintegração familiar poderão trazer uma nova relação entre famílias e instituições, a qual poderá levar desafios à equipe técnica, que, segundo a atual lei, será responsável pela reintegração. 


\section{Considerações finais}

Este trabalho ressalta um movimento gerado pela nova Lei Nacional de Adoção na prática dos profissionais entrevistados, trazido principalmente pela valorização da palavra da criança e do adolescente, por uma relação mais próxima com a família e, consequentemente, pela construção do plano de atendimento individual. Os profissionais entrevistados parecem demonstrar sintonia com os parâmetros apontados pela NLNA.

Pode-se ainda considerar, mediante as falas dos profissionais, a angústia mobilizada diante das situaçôes vividas pelas crianças e pelos adolescentes, que são parte do dia a dia do trabalho. Nesse sentido, entende-se que os profissionais, mobilizados por histórias que muitas vezes mostram a crueldade e o abuso de um adulto sobre uma criança ou um adolescente, deveriam contar com espaços de acolhida de seu sofrimento, as quais podem ser alcançadas com supervisões periódicas. Tendo em vista que essa angústia, se não trabalhada adequadamente, pode trazer dificuldades para os profissionais, podendo levar ao afastamento da instituição, licenças ou mesmo formas de atuação menos reflexivas.

Passados dois anos da promulgação da NLNA, o que pode ser destacado aqui é a valorização da escuta da criança e, ou, do adolescente, a qual foi referida como uma ação presente no acolhimento institucional. Isso é, sem dúvida, resultado de novas práticas profissionais, indicando a superação do modelo mais tradicional de institucionalização de crianças, permitindo a construção de uma melhor vivência do acolhimento.

É importante destacar a necessidade de permanência de estudos acerca do uso do plano de atendimento individual, como um instrumento que possibilita a verdadeira escuta da criança e do adolescente, pois, sendo um instrumento dinâmico e que trata da história de vida de crianças, adolescentes e famílias, não se pode correr o risco de torná-lo mais um procedimento burocrático no interior das instituições.

Entende-se que dar voz aos profissionais que vivenciam o acolhimento institucional foi uma escolha metodológica que apresenta apenas uma das muitas perspectivas de olhar para essa problemática, certamente, sem o intuito de esgotá-la. Nesse sentido, com vistas a superar os limites do estudo, outras pesquisas que pudessem enfocar a compreensão da família, das crianças e dos adolescentes, por exemplo, sobre as questôes que perpassam o acolhimento institucional, principalmente experiências após a Nova Lei Nacional, podem trazer diferentes nuances para esse tema. Outros recursos metodológicos também poderiam ser utilizados, como grupos focais ou estudos de caso, 
por exemplo, os quais certamente ampliam as possibilidades de abordar e compreender o tema, a partir dos olhares de quem vivencia a realidade do acolhimento.

Por fim, esta pesquisa cumpre seus objetivos, a partir do retorno de seus resultados às instituições e segmentos envolvidos com a temática, os quais podem se constituir em reflexões para novas intervenções direcionadas à clientela, aos profissionais, à relação entre instituição e família, e instituição e Judiciário. Este se constitui, certamente, num momento especial, uma vez que os resultados evidenciaram a transformação do cotidiano de acolhimento institucional e sua sintonia com os preceitos da nova lei, aspecto que certamente pode desafiar à construção de novas ações.

\section{Referências}

Arpini, D. M. \& Quintana, A. M. (2009). Família e instituições de abrigo: reconstruindo relações. In D. M. Arpini (Org.). Psicologia, família e instituição. (pp. 9-28). Santa Maria: Editora UFSM.

Arpini, D. M. (2003). Repensando a perspectiva institucional e a intervenção em abrigos para crianças e adolescentes. Psicologia, Ciência e Profissão, 21 (3), 70-75.

Arpini, D. M. (2013). A nova Lei Nacional de Adoção e os desafios para a compreensão da família. In A. C. Siqueira, F. Jaeger \& C. S. Kruel (Orgs.). Familia e violência: conceitos, práticas e reflexôes críticas. (pp. 67-76). Curitiba: Juruá.

Associação Brasileira Terra dos Homens. (2002). Do abrigo à família. (3a ed.). Rio de Janeiro: Booklink.

Azambuja, M. R. F. (2002). A adoção sob a perspectiva da doutrina da proteção integral. In D. Zimerman \& A. C. M. Coltro (Orgs). Aspectos psicológicos na prática jurídica. (pp. 302-317). Campinas: Millennium.

Azôr, A. M. G. C. C. V. \& Vectore, C. (2008). Abrigar/desabrigar: conhecendo o papel das famílias nesse processo. Estudos de Psicologia, 25 (1), 77-89.

Bardin, L. (2004). Análise de conteúdo. Lisboa: Ediçōes 70. 
Bernardi, D. C. F. (2005). Concepçôes de infância em relatórios psicológicos judiciais. Dissertação de Mestrado em Psicologia Social, Pontifícia Universidade Católica, São Paulo.

Bernardi, D. C. F. (2010). Famílias em situação de vulnerabilidade. In Dayse C. F. Bernardi (Coord.). Cada caso é um caso: a voz das crianças e dos adolescentes em acolhimento institucional. (pp. 37-44). São Paulo: Associação Fazendo História. Disponível em: http://www.fazendohistoria.org.br/downloads/5_ cada_casa_e_um_caso.pdf.

Ferreira, A. B. H. (1977). Abrigar. In Aurélio B. H. Ferreira. Minidicionário da lingua portuguesa. Rio de Janeiro: Nova Fronteira.

Fonseca, C. (2002). Mãe é uma só? Reflexões em torno de alguns casos brasileiros. Revista Psicologia USP, 13 (2), 49-68.

Goffman, E. (1961). Manicômios, prisões e conventos. São Paulo: Perspectiva.

Janczura, R. (2008). Abrigos e políticas públicas: as contradiçôes na efetivação dos direitos da criança e do adolescente. Tese de Doutorado em Serviço Social, Pontifícia Universidade Católica do Rio Grande do Sul, Porto Alegre.

Lei n. 12.010. (2009, 3 de agosto). Dispõe sobre adoção; altera as Leis $\mathrm{n}^{\mathrm{os}}$ 8.069, de 13 de julho de 1990 - Estatuto da Criança e do Adolescente, 8.560, de 29 de dezembro de 1992; revoga dispositivos da Lei $\mathrm{n}^{\mathrm{o}}$ 10.406, de 10 de janeiro de 2002 - Código Civil, e da Consolidação das Leis do Trabalho CLT, aprovada pelo Decreto-Lei no 5.452 , de $1^{\circ}$ de maio de 1943; e dá outras providências. Diário Oficial da Uniāo. Disponível em: http://www.planalto. gov.br/ccivil_03/_Ato2007-2010/2009/Lei/L12010.htm.

Lei n. 8.069. (1990, 13 de julho). Dispóe o Estatuto da Criança e do Adolescente e dá outras providências. Diário Oficial da Uniāo. Disponível em: http://www. planalto.gov.br/ccivil_03/leis/L8069.htm.

Marin, I. S. K. (1999). Febem, família e identidade: o lugar do outro (2a ed.). São Paulo: Escuta.

Paiva, L. D. (2004). Adoção: significados e possibilidades. São Paulo: Casa do Psicólogo.

Petrini, J. C. (2003). Pós-modernidade e família: um itinerário de compreensão. Bauru: Edusc. 
Resolução n. 016/2000. (2000, 20 de dezembro). Dispõe sobre a realização de pesquisa em Psicologia com seres humanos. Brasília: Conselho Federal de Psicologia.

Resolução n. 196. (1996, 10 de outubro). Diretrizes e normas regulamentadoras de pesquisas envolvendo seres humanos. Brasília: Conselho Nacional de Saúde.

Rizzini, I. \& Rizzini, I. (2004). A institucionalização de crianças no Brasil: percurso histórico e desafios do presente. São Paulo: Loyola.

Rossetti-Ferreira, M. C., Solon, L. A. G. \& Almeida, I. G. (2010). A delicada arte da conversa e da escuta. In Dayse C. F. Bernardi (Org.). Cada caso é um caso: a voz das crianças e dos adolescentes em acolhimento institucional. (pp. 6173). São Paulo: Associação Fazendo História. Disponível em: http://www. fazendohistoria. org.br/downloads/5_cada_casa_e_um_caso.pdf.

Sayão, Y. (2010). Desenvolvimento infantil e abrigamento. In Dayse C. F. Bernardi (Coord). Cada caso é um caso: estudos de caso, projetos de atendimento (pp. 117-123). São Paulo: Associação Fazendo História. Disponível em: http://www.fazendohistoria.org.br/downloads/5_cada_casa_e_um_caso.pdf.

Silva, E. R. A. (2004). A construção do direito à convivência familiar e comunitária no Brasil. In Enid R. A. Silva. O direito à convivência familiar e comunitária: os abrigos para crianças e adolescentes no Brasil. (pp. 287-302). Brasília: IPEA.

Silva, E. R. A., Mello, S. G. \& Aquino, L. M. C. (2004). Os abrigos para crianças e adolescentes e a promoção do direito à convivência familiar e comunitária. In Enid R. A. Silva (Coord.). $O$ direito à convivência familiar e comunitária: os abrigos para crianças e adolescentes no Brasil. (pp. 209-242). Brasília: IPEA.

Silva, M. L.; Polli, R. G.; Sobrosa, G.M. R.; Arpini, D. M. \& Dias, A. C. G. (2012). Da normatização a compreensão: caminhos construídos para a intervenção familiar. Mudanças, 20 (1-2), 13-21.

Silva, R. (2002). O que é institucionalização. In Associação Brasileira Terra dos Homens. Do abrigo à família. (3a ed.). (pp. 9-21). Rio de Janeiro: Booklink.

Siqueira, A. C. \& Dell'Aglio, D. D. (2006). O impacto da institucionalização na infância e na adolescência: uma revisão de literatura. Psicologia e Sociedade, 18 (1) , 71-80. 
Temer, C. T. (2008). Pai, conta historinha? In Immaculada Lopez. Fazendo minha história: guia de ação para abrigos e colaboradores (pp. 1-3). São Paulo: Associação Fazendo História. Disponível em: http://www.fazendohistoria. org.br/ downloads/guiafmh.pdf.

Turato, E. R. (2003). Tratado da metodologia da pesquisa clínico-qualitativa. Petrópolis: Vozes.

Winnicott, D. W. (2005). Privação e delinquência (4a ed.). São Paulo: Martins Fontes. 